\title{
LETTERS
}

\section{Routine use of episiotomy with forceps should not be encouraged}

Muraca and colleagues show an association between forceps delivery without episiotomy and rising severe perineal trauma. ${ }^{1}$ This large, retrospective study of administrative data examined hospital births only. The study does not report a breakdown by provider type, though the database from the Canadian Institute for Health Information (CIHI) includes providers. Data on home births are absent from the $\mathrm{CIHI}$ database but available from other sources. In the 4-year study by Janssen and colleagues of all home births in British Columbia, rates of episiotomy and third- or fourth-degree tears were lower than in Muraca and colleagues' study, as were rates of instrumentation (i.e., use of forceps and vacuum) after transfer (i.e., from intended home birth to hospital for cause). ${ }^{2}$

A retrospective study of administrative data cannot provide causal inferences. Muraca and colleagues show us that something is going on that needs explanation. But other temporal changes are also taking place, that is, increasing maternal age, and steadily rising rates of epidural use and electronic fetal monitoring. Importantly, episiotomy use declined in spontaneous vaginal deliveries, which represented more than $85 \%$ of deliveries in the study by Muraca and colleagues, associated with corresponding decline in thirdand fourth-degree tears. ${ }^{1}$ By contrast, the main conclusion of the study is based on forceps deliveries among nulliparous women and those attempting vaginal birth after cesarean, which accounted for $2.9 \%$ of deliveries included in the study.

In a hospital where clinicians were urged to separate the decision to use forceps from use of episiotomy, Ecker and colleagues found the rate of third-and fourth-degree tears was dramatically reduced among nulliparous women. ${ }^{3}$ One of us led the only randomized controlled trial of episiotomy use in North America, which showed a powerful association between episiotomy use and third- and fourth-degree tears. ${ }^{4}$ Of 47 primiparous women, 46 had third- and fourth-degree tears in the presence of median episiotomy. Physicians with the highest episiotomy rates had the highest rates of third- and fourth-degree tears and used instrumentation and cesarean more often in women who were not randomly assigned because of risk issues that arose, but who were still followed and whose data were analyzed.

\section{Michael C. Klein MD}

Emeritus professor of family practice, University of British Columbia, Vancouver, BC

\section{Janusz Kaczorowski PhD}

Professor of family and emergency medicine, Université de Montréal and Centre de recherche du Centre hospitalier de l'Université de Montréal, Montréal, Que.

Cite as: CMAJ 2020 February 24; 192:E190. doi: 10.1503/cmaj.74132

\section{References}

1. Muraca GM, Liu S, Sabr Y, et al. Episiotomy use among vaginal deliveries and the association with anal sphincter injury: a population-based retrospective cohort study. CMAJ 2019;191:E1149-58.

2. Janssen P, Saxell L, Page L, et al. Outcomes of planned home birth with registered midwives versus planned hospital birth with a midwife or a physician. CMAJ 2009;181:377-83.

3. Ecker JL, Tan WM, Bansal RJ, et al. Is there a benefit to episiotomy at operative vaginal delivery? Observations over ten year in a stable population. Am J Obstet Gynecol 1997;176:411-4.

4. Klein MC, Gauthier RJ, Robbins JM, et al. Relationship of episiotomy to perineal trauma and morbidity, sexual dysfunction and pelvic floor relaxation. Am J Obstet Gynecol 1994;171:591-8.

Competing interests: None declared. 